\title{
Uses of the Buys-Ballot Table in Time Series Analysis
}

\author{
Iheanyi S. Iwueze ${ }^{1}$, Eleazar C. Nwogu ${ }^{1}$, Ohakwe Johnson ${ }^{2}$, Jude C. Ajaraogu ${ }^{3}$ \\ ${ }^{1}$ Department of Statistics, Federal University of Technology, Owerri, Nigeria \\ ${ }^{2}$ Department of Mathematics and Statistics, Anambra State University, Uli, Nigeria \\ ${ }^{3}$ Department of Mathematics and Statistics, Federal Polytechnic, Owerri, Nigeria \\ E-mail: isiwueze@yahoo.com \\ Received December 14, 2010; revised March 30, 2011; accepted April 3, 2011
}

\begin{abstract}
Uses of the Buys-Ballot table for choice of appropriate transformation (using the Bartlett technique), assessment of trend and seasonal components and choice of model for time series decomposition are discussed in this paper. Uses discussed are illustrated with numerical examples when trend curve is linear, quadratic and exponential.
\end{abstract}

Keywords: Buys-Ballot Table, Trend Assessment, Assessment of Seasonality, Periodic Averages, Seasonal Averages, Data Transformation, Choice of Model

\section{Introduction}

A time series is a collection of observations made sequentially in time. Examples occur in a variety of fields, ranging from economics to engineering and methods of analyzing time series constitute an important area of statistics [1]. Time series analysis comprises methods that attempt to understand such time series, often either to understand the underlying context of the data points (Where did they come from? What generated them?), or to make forecasts. Time series forecasting is the use of a model to forecast or predict future events based on known past events.

Methods for time series analyses are often divided into three classes: descriptive methods, time domain methods and frequency domain methods. Frequency domain methods centre on spectral analysis and recently wavelet analysis [2,3], and can be regarded as model-free analyses. Time domain methods [4,5] have a distributionfree subset consisting of the examination of autocorrelation and cross-correlation analysis.

Descriptive methods $[1,6]$ involve the separation of an observed time series into components representing trend (long term direction), the seasonal (systematic, calendar related movements), cyclical (long term oscillations or swings about the trend) and irregular (unsystematic, short term fluctuations) components. The descriptive method is known as time series decomposition. If short period of time are involved, the cyclical component is superimposed into the trend [1] and the observed time series $\left(X_{t}\right.$, $t=1,2, \cdots, n)$ can be decomposed into the trend-cycle component $\left(M_{t}\right)$, seasonal component $\left(S_{t}\right)$ and the irregular/residual component $\left(e_{t}\right)$.

Decomposition models are typically additive or multiplicative, but can also take other forms such as pseudoadditive/mixed (combining the elements of both the additive and multiplicative models).

Additive Model: $X_{t}=M_{t}+S_{t}+e_{t}$

Multiplicative Model: $X_{t}=M_{t} \times S_{t} \times e_{t}$

Pseudo-Additive/Mixed Model; $X_{t}=M_{t} \times S_{t}+e_{t}$

The pseudo-additive model is used when the original time series contains very small or zero values. For this reason, this paper will discuss only the additive and multiplicative models.

As far as the traditional method of decomposition is concerned (to be referred to as the Least Squares Method (LSE)), the first step will usually be to estimate and eliminate $M_{t}$ for each time period from the actual data either by subtraction for Equation (1) or division for Equation (2). The de-trended series is obtained as $X_{t}$ $-\hat{M}_{t}$ for Equation (1) or $X_{t} / \hat{M}_{t}$ for Equation (2). In the second step, the seasonal effect is obtained by estimating the average of the de-trended series at each season. The de-trended, de-seasonalized series is obtained as $X_{t}-\hat{M}_{t}-\hat{S}_{t}$ for Equation (1) or $X_{t} /\left(\hat{M}_{t} \hat{S}_{t}\right)$ for Equation (2). This gives the residual or irregular component. Having fitted a model to a time series, one often wants to see if the residuals are purely random. For detailed dis- 
cussion of residual analysis, see [4,7].

It is always assumed that the seasonal effect, when it exists, has periods. That is, it repeats after $s$ time periods.

$$
S_{t+s}=S_{t} \text {, for all } t
$$

For Equation (1), it is convenient to make the further assumption that the sum of the seasonal components over a complete period is zero.

$$
\sum_{j=1}^{s} S_{t+j}=0
$$

Similarly, for Equations (2) and (3), the convenient variant assumption is that the sum of the seasonal components over a complete period is $s$.

$$
\sum_{j=1}^{s} S_{t+j}=s
$$

It is also assumed that the irregular component $e_{t}$ is the Gaussian $N\left(0, \sigma_{1}^{2}\right)$ white noise for Equation (1), while for Equation (2), $e_{t}$ is the Gaussian $N\left(1, \sigma_{2}^{2}\right)$ white noise.

This paper discusses the uses of the Buys-Ballot table for 1) choice of appropriate transformations (using the Bartlett technique) 2) assessment of trend and seasonal components and 3) choice of model for time series decomposition. We describe in great detail the Buys-Ballot table in Section 2 for better understanding of the methods used to achieve these objectives.

When any of the assumptions underlying the time series analysis is violated, one of the options available to an analyst is to transform the study series. The choice of appropriate transformation for a study series using BuysBallot table is described in Section 3. The presence and nature of trend and seasonal component of a study series can be inferred from the plot and values of the periodic /annual and seasonal averages. Assessment of trend and seasonal component of the actual series from the BuysBallot table was discussed in Sections 4 and 5 respectively. A major problem in the use of the descriptive time series analysis is the choice of appropriate model for time series decomposition. This problem was addressed using Buys-Ballot table in Section 6. Numerical examples are also given to illustrate these uses.

\section{Buys-Ballot Table}

A Buys-Ballot table summarizes data to highlight seasonal variations (Table 1). Normally, each line is one period (usually a year) and each column is a season of the period/year (4 quarters, 12 months, etc), A cell, $(i, j)$, of this table contains the mean value for all observations made during the period $i$ at the season $j$. To analyse the data, it is helpful to include the period and seasonal totals $\left(T_{i .}\right.$ and $\left.T_{. j}\right)$, period and seasonal averages $\left(\bar{X}_{i .}\right.$ and $\left.\bar{X}_{. j}\right)$, period and seasonal standard deviations $\left(\hat{\sigma}_{i .}\right.$ and $\left.\hat{\sigma}_{. j}\right)$, as part of the Buys-Ballot table. Also included for purposes of analysis are the grand total $\left(T_{. .}\right)$, grand mean $\left(\bar{X}_{. .}\right)$and pooled standard deviation $\left(\hat{\sigma}_{. .}\right)$. .[8] credits these arrangements of the table to [9], hence the table has been called the Buys-Ballot table in the literature.

For easy understanding of Table 1, we define the row and column totals, averages and standard deviations as follows:

\begin{tabular}{|c|c|c|c|c|c|c|c|c|c|}
\hline \multirow[b]{2}{*}{ Period $(i)$} & \multicolumn{6}{|c|}{ Season $(j)$} & \multirow{2}{*}{$T_{i}$} & \multirow{2}{*}{$\bar{X}_{i .}$} & \multirow{2}{*}{$\hat{\sigma}_{i .}$} \\
\hline & 1 & 2 & $\ldots$ & $j$ & $\ldots$ & $s$ & & & \\
\hline 1 & $X_{1}$ & $X_{2}$ & $\ldots$ & $X_{j}$ & $\ldots$ & $X_{s}$ & $T_{1 .}$ & $\bar{X}_{1 .}$ & $\hat{\sigma}_{1 .}$ \\
\hline 2 & $X_{s+1}$ & $X_{s+2}$ & $\ldots$ & $X_{s+j}$ & $\ldots$ & $X_{2 s}$ & $T_{2 .}$ & $\bar{X}_{2}$ & $\hat{\sigma}_{2}$ \\
\hline 3 & $X_{2 s+1}$ & $X_{2 s+2}$ & $\ldots$ & $X_{2 s+j}$ & $\ldots$ & $X_{3 s}$ & $T_{3 .}$ & $\bar{X}_{3 .}$ & $\hat{\sigma}_{3 .}$ \\
\hline$\ldots$ & $\ldots$ & $\ldots$ & $\ldots$ & $\ldots$ & $\ldots$ & $\ldots$ & $\ldots$ & $\ldots$ & $\ldots$ \\
\hline$i$ & $X_{(i-1))^{\prime}+1}$ & $X_{(i-1) \times+2}$ & $\ldots$ & $X_{(i-1) x+j}$ & $\ldots$ & $X_{(i-1) s+s}$ & $T_{i .}$ & $\bar{X}_{i .}$ & $\hat{\sigma}_{i .}$ \\
\hline$\ldots$ & $\ldots$ & $\ldots$ & $\ldots$ & $\ldots$ & $\ldots$ & $\ldots$ & $\ldots$ & $\ldots$ & $\ldots$ \\
\hline$m$ & $X_{(m-1) s+1}$ & $X_{(m-1)+2}$ & $\ldots$ & $X_{(m-1)+j}$ & $\ldots$ & $X_{m s}$ & $T_{m}$. & $\bar{X}_{m .}$ & $\hat{\sigma}_{m .}$ \\
\hline$T_{. j}$ & $T_{.1}$ & $T_{2}$ & $\ldots$ & $T_{. j}$ & $\ldots$ & $T_{s}$ & $T$ & - & - \\
\hline $\bar{X}_{. j}$ & $\bar{X}_{1}$ & $\bar{X}_{2}$ & $\ldots$ & $\bar{X}_{. j}$ & $\ldots$ & $\bar{X}_{s}$ & - & $\bar{X}$ & - \\
\hline$\hat{\sigma}_{. j}$ & $\hat{\sigma}_{.1}$ & $\hat{\sigma}_{2}$ & $\ldots$ & $\hat{\sigma}_{. j}$ & $\ldots$ & $\hat{\sigma}_{s}$ & - & - & $\hat{\sigma}_{.}$ \\
\hline
\end{tabular}

$$
\begin{aligned}
& T_{i .}=\sum_{j=1}^{s} X_{(i-1) s+j}, \quad i=1,2, \cdots, m, \\
& T_{. j}=\sum_{i=1}^{m} X_{(i-1) s+j}, \quad j=1,2, \cdots, s,
\end{aligned}
$$

Table 1. Buys-Ballot Table. 


$$
\begin{aligned}
& T_{. .}=\sum_{i=1}^{m} T_{i .}=\sum_{j=1}^{s} T_{. j}, \bar{X}_{i .}=\frac{T_{i .}}{s}, i=1,2, \cdots, m, \\
& \bar{X}_{. j}=\frac{T_{. j}}{m}, j=1,2, \cdots, s, \bar{X}_{. .}=\frac{T_{. .}}{m s}=\frac{T_{. .}}{m s}, n=m s, \\
& \hat{\sigma}_{i .}=\sqrt{\frac{1}{s-1} \sum_{j=1}^{s}\left(X_{(i-1) s+j}-\bar{X}_{i .}\right)^{2}}, i=1,2, \cdots, m \\
& \hat{\sigma}_{. j}=\sqrt{\frac{1}{m-1} \sum_{i=1}^{m}\left(X_{(i-1) s+j}-\bar{X}_{. j}\right)^{2}}, j=1,2, \cdots, s \\
& \hat{\sigma}=\sqrt{\frac{1}{n-1} \sum_{i=1}^{m} \sum_{j=1}^{s}\left(X_{(i-1) s+j}-\bar{X}_{. .}\right)^{2}}
\end{aligned}
$$

where $X_{t}, t=1,2, \cdots, n$ is the observed value of the series, $m$ is the number of periods/years, $s$ is the periodicity, and $n=m s$ is the total number of observations /sample size.

Finally, Buys-Ballot table is used to estimate the trend component and seasonal indices from the chosen descriptive time series model. This method, called BuysBallot estimation procedure uses the periodic means $\left(\bar{X}_{i,}, i=1,2, \cdots, m\right)$ and the overall mean $\left(\bar{X}_{. .}\right)$to estimate the trend component. Seasonal means $\left(\bar{X}_{. j}\right.$, $j=1,2, \cdots, m)$ and the overall mean are used to estimate the seasonal indices. The advantages of the Buys-Ballot estimation procedure are that 1 ) it computes trend easily, 2) gets over the problem of de-trending a series before computing the estimates of the seasonal effects and 3) estimates the error variance without necessarily decomposing the series. For further details on the Buys-Ballot estimation procedure, see [10-14].

\section{Choice of Appropriate Transformation}

Transformation is a mathematical operation that changes the measurement scale of a variable. Reasons for transformation include stabilizing variance, normalizing, reducing the effect of outliers, making a measurement scale more meaningful, and to linearize a relationship. For further details on reasons for transformation, see $[3,14]$. Many time series analyst assume no rmality and it is well known that variance stabilization implies normality of the series. The most popular and common are the powers of transformations such as $\log _{e} X_{t}, \log _{e} X_{t}$, $1 / X_{t}, 1 / \sqrt{X_{t}}, X_{t}^{2}, 1 / X_{t}^{2}$. Selecting the best trans- formation can be a complex issue and the usual statistical technique used is to estimate both the transformation and required model for the transformed $X_{t}$ at the same time [15].

[16] have shown how to apply Bartlett transformation technique [17] to time series data using the Buys-Ballot table and without considering the time series model structure. The relation between variance and mean over several groups is what is needed. If we take random samples from a population, the means and standard deviations of these samples will be independent (and thus uncorrelated) if the population has a normal distribution [18]. Furthermore, if the mean and standard deviation are independent, the distribution is normal.

[16] showed that Bartlett's transformation for time series data is to regress the natural logarithms of the group standard deviations $\left(\hat{\sigma}_{i,}, i=1,2, \cdots, m\right)$ against the natural logarithms of the group means $\left(\bar{X}_{i,}, i=1,2, \cdots, m\right)$ and determine the slope, $\beta$, of the relationship.

$$
\log _{e} \hat{\sigma}_{i .}=\alpha+\beta \log _{e} \bar{X}_{i .}+\text { error }
$$

For non-seasonal data that require transformation, we split the observed time series $X_{t}, t=1,2, \cdots, n$ chronologically into $\mathrm{m}$ fairly equal different parts and compute $\left(\bar{X}_{i .}, i=1,2, \cdots, m\right)$ and $\left(\hat{\sigma}_{i .}, i=1,2, \cdots, m\right)$ for the parts. For seasonal data with the length of the periodic interval, $s$, the Buys-Ballot table naturally partitions the observed data into m periods or rows for easy application. [16] showed that Bartlett's transformation may also be regarded as the power transformation

$$
Y_{t}=\left\{\begin{array}{l}
\log _{e} X_{t}, \quad \beta=1 \\
X_{t}^{(1-\beta)}, \beta \neq 1
\end{array}\right.
$$

Summary of transformations for various values of $\beta$ is given in Table 2. However, [16] concluded that it is better to use the estimated value of the slope, $\beta$, directly in the power transformation (Equation (8)) than to approximate to the known and popular logarithmic, square root, inverse, inverse of the square root, squares and inverse of the squares transformations.

An example that requires logarithmic transformation is the Nigerian Stock Exchange (NSE) All Shares Index (1985 - 2005) that is listed as Appendix A [19]. Summary of the regression analysis of $\log _{e}\left(\hat{\sigma}_{I}\right)$ on $\log _{e}\left(\bar{X}_{i}\right), \quad i=1,2, \cdots, 21$ is given in Table 3 .

Table 2. Bartlett's transformation for some values of $\boldsymbol{\beta}$.

\begin{tabular}{cccccccc}
\hline S/No & 1 & 2 & 3 & 4 & 5 & 6 & 7 \\
\hline$\beta$ & 0 & $1 / 2$ & 1 & $3 / 2$ & 2 & 3 & -1 \\
Transformation & No transformation & $\sqrt{X_{t}}$ & $\log _{e} X_{t}$ & $1 / \sqrt{X_{t}}$ & $1 / X_{t}$ & $1 / X_{t}^{2}$ & $X_{t}^{2}$ \\
\hline
\end{tabular}


Table 3. Regression analysis of $\log _{e} \hat{\sigma}_{i .}$ on $\log _{e} \bar{X}_{i .}, i=1,2, \mathrm{~L}, 21$ for various transformations of the Nigerian Stock Exchange (NSE) All Shares Index (1985-2005).

\begin{tabular}{ccccc}
\hline & & & \multicolumn{2}{c}{$t-$ test for $\hat{\beta}=1.0$} \\
\cline { 3 - 5 } Transformations & Regression equation & $R^{2}$ & df & value \\
\hline$X_{t}:$ Original & $\log _{e} \hat{\sigma}_{i}=-2.5797+1.0260 \log _{e} \bar{X}_{i}$ & 0.94 & 19 & 0.44 \\
$Y_{t}=\log _{e} X_{t}$ & $\log _{e} \hat{\sigma}_{i}=-2.8857+0.2490 \log _{e} \bar{Y}_{i}$ & 0.02 & 19 & $N / A$ \\
$W_{t}=X_{t}^{(1-\hat{\beta})}, \hat{\beta}=1.0260$ & $\log _{e} \hat{\sigma}_{i}=-6.2186+0.0794 \log _{e} \bar{W}_{i}$ & 0.00 & 19 & N/A \\
\hline
\end{tabular}

It is clear from Table 3 that we can approximate the value of $\hat{\beta}=1.0260$ to $\hat{\beta} \approx 1.0$ and the suitable transformation using Table 2 is $Y_{t}=\log _{e} X_{t}$. Regression analysis summaries for $Y_{t}=\log _{e} X_{t}$ and $W_{t}=X_{t}^{(1-\hat{\beta})}$, $\hat{\beta}=1.0260$ are also given in Table 3. The transformation $W_{t}=X_{t}^{(1-\hat{\beta})}, \hat{\beta}=1.0260$ surely removes the relationships between the standard deviations and the means for the row/yearly groupings.

\section{Assessment of Trend}

The time plot of a time series, according to [1] reveals the nature of the trend which can describe the pattern in the series. Among other features, the time plot of the periodic means follows the same pattern as the plot of the entire series with respect to the trend. Therefore, instead of looking at the plot of the entire series, one may look at only the plot of the period/annual means in order to choose the appropriate trend. We use the following examples to illustrate this.

\subsection{Linear Trend}

The data of Table 4 (linear trend and additive model) and Figure $\mathbf{1}$ is a simulation of 100 values from the additive model

$$
X_{t}=a+b t+S_{t}+e_{t}
$$

with $a=5.0, \quad b=0.2, \quad S_{1}=-1.5, \quad S_{2}=2.5, \quad S_{3}=3.5$, $S_{4}=-4.5$ and $e_{t}$ being Gaussian $N(0,1)$ white noise. The data of Table 4 (linear trend and multiplicative model) and Figure 2 is a simulation of 100 values from the multiplicative model

$$
X_{t}=(a+b t) \times S_{t} \times e_{t}
$$

with $a=5.0, \quad b=0.2, \quad S_{1}=0.6, \quad S_{2}=1.1, \quad S_{3}=0.9$, $S_{4}=1.4$ and $e_{t}$ being Gaussian $N(1.0,0.01)$ white noise. Listed in Table 4 are the periodic/row means $\left(\bar{X}_{i}, i=1,2, \cdots, m\right)$ of the simulated data, while the time plots of the actual series and periodic/row means are shown in Figures $\mathbf{1}$ and 2, respectively. It is clear that the time plot of $\bar{X}_{i}$. for data with linear trend curve mimics the time plot of the entire series and the row averages $\left(\bar{X}_{i .}\right)$ can therefore, be used to estimate trend.

The estimate of the parameters of the trend of the entire series can be determined from the estimate of the trend of the periodic means by recognizing that periodic averages are centred at the midpoints of the periodic intervals. Thus, while successive values in the actual series are one unit of time apart starting from $t=1$, successive values in periodic average series $\left(\bar{X}_{i}\right)$ are $\mathrm{s}$ units of time apart starting from $t=(s+1) / 2$. Thus, periodic averages are derived from the original series by translation of the original series by a factor $((s+1) / 2)$ and dilation by a factor $s$. That is, periodic averages, $\bar{X}_{i .}, i=1,2, \cdots, m$ may be looked at as the values of the original series at times $t_{i}, i=1,2, \cdots, m$. That is,

$$
\bar{X}_{i .}=X_{t_{i}}=a+b t_{i}
$$

where $t_{i}=\frac{s+1}{2}, \frac{3 s+1}{2}, \frac{5 s+1}{2}, \cdots, \frac{(2 m-1) s+1}{2}$, for $i=1,2,3, \cdots, m$, Hence,

$$
\begin{aligned}
\bar{X}_{i .} & =X_{t_{i}}=a+b\left(\frac{(2 i-1) s+1}{2}\right) \\
& =a-b\left(\frac{s-1}{2}\right)+(b s) i \\
& =a^{\prime}+b^{\prime} i
\end{aligned}
$$

where $\quad a^{\prime}=a-b\left(\frac{s-1}{2}\right), \quad b^{\prime}=b s \quad$ or $\quad b=b^{\prime} / s$, $a=a^{\prime}+b\left(\frac{s-1}{2}\right)$.

As an illustration, we observe from Figure 1 that $s=4, b^{\prime}=0.8003, a^{\prime}=4.6971$. Hence, $b=b^{\prime} / s=0.8003 / 4$ $=0.2001, a=a^{\prime}+b((s-1) / 2)=4.6971+0.2001((4-1) / 2)$ $=4.9972$.

The estimate of the parameters of the trend of the entire series can be determined from the estimate of the trend of the periodic means in quadratic [12] and exponential [13] trend curves as shown below. 
Table 4. Periodic means of the simulated series.

\begin{tabular}{|c|c|c|c|c|c|c|}
\hline \multirow{2}{*}{$\begin{array}{c}\text { Period/Year } \\
(i)\end{array}$} & \multicolumn{2}{|c|}{ Linear Equations (9) and (10) } & \multicolumn{2}{|c|}{ Quadratic Equations (13) and (14) } & \multicolumn{2}{|c|}{ Exponential Equations (16) and (17) } \\
\hline & Add. $\left(\bar{X}_{i .}\right)$ & Mult. $\left(\bar{X}_{i .}\right)$ & Add. $\left(\bar{X}_{i .}\right)$ & Mult. $\left(\bar{X}_{i}\right)$ & Add. $\left(\bar{X}_{i .}\right)$ & Mult. $\left(\bar{X}_{i .}\right)$ \\
\hline 1 & 5.631 & 5.950 & 56.900 & 8.180 & 10.647 & 11.260 \\
\hline 2 & 6.106 & 6.396 & 67.800 & 19.830 & 11.197 & 11.580 \\
\hline 3 & 6.947 & 6.147 & 90.200 & 33.760 & 12.187 & 10.710 \\
\hline 4 & 8.260 & 9.288 & 124.300 & 90.800 & 13.728 & 15.680 \\
\hline 5 & 8.320 & 7.340 & 168.400 & 101.000 & 14.101 & 12.210 \\
\hline 6 & 9.568 & 10.060 & 224.800 & 190.000 & 15.755 & 16.580 \\
\hline 7 & 10.359 & 10.911 & 292.000 & 264.000 & 17.053 & 18.020 \\
\hline 8 & 11.267 & 11.881 & 370.500 & 347.200 & 18.576 & 19.670 \\
\hline 9 & 11.519 & 10.417 & 459.600 & 365.000 & 19.562 & 17.450 \\
\hline 10 & 13.019 & 14.206 & 561.100 & 577.000 & 21.922 & 24.230 \\
\hline 11 & 13.396 & 14.125 & 672.600 & 667.000 & 23.299 & 24.700 \\
\hline 12 & 13.937 & 12.031 & 795.600 & 629.000 & 24.989 & 21.380 \\
\hline 13 & 14.520 & 13.255 & 929.800 & 785.000 & 26.883 & 24.280 \\
\hline 14 & 16.377 & 18.476 & 1076.400 & 1203.000 & 30.227 & 34.800 \\
\hline 15 & 16.880 & 18.418 & 1232.900 & 1319.000 & 32.408 & 35.700 \\
\hline 16 & 17.583 & 17.168 & 1400.800 & 1324.000 & 34.995 & 34.100 \\
\hline 17 & 18.712 & 20.478 & 1580.400 & 1720.000 & 38.232 & 42.460 \\
\hline 18 & 19.977 & 24.094 & 1771.200 & 2168.000 & 41.850 & 51.580 \\
\hline 19 & 20.258 & 20.132 & 1972.300 & 1940.000 & 44.740 & 44.800 \\
\hline 20 & 19.843 & 14.640 & 2183.900 & 1517.000 & 47.222 & 34.110 \\
\hline 21 & 21.522 & 23.094 & 2408.800 & 2558.000 & 52.110 & 56.400 \\
\hline 22 & 21.978 & 20.834 & 2643.600 & 2448.000 & 56.098 & 53.200 \\
\hline 23 & 22.310 & 16.033 & 2889.600 & 1958.000 & 60.330 & 42.130 \\
\hline 24 & 24.741 & 30.636 & 3148.800 & 3983.000 & 67.052 & 85.100 \\
\hline 25 & 24.467 & 23.045 & 3416.500 & 3156.000 & 71.492 & 67.200 \\
\hline $\bar{X}$ & 15.100 & 15.162 & 1221.600 & 1174.900 & 32.266 & 32.373 \\
\hline
\end{tabular}

Note: Add = Additive; Mult = Multiplicative

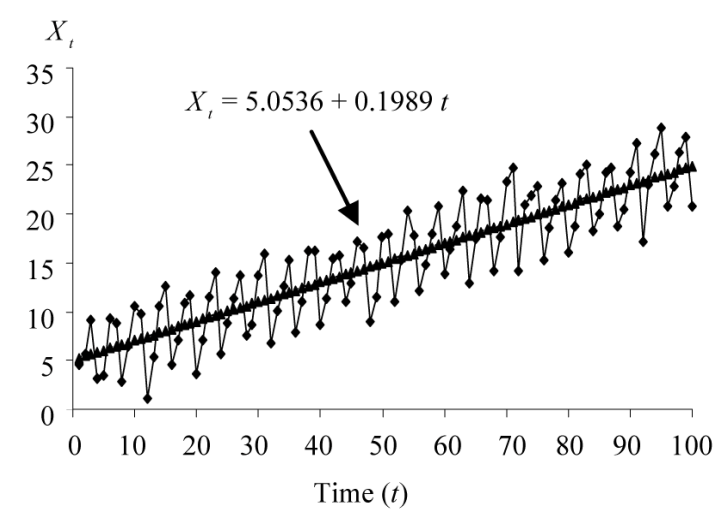

(a) Actual series

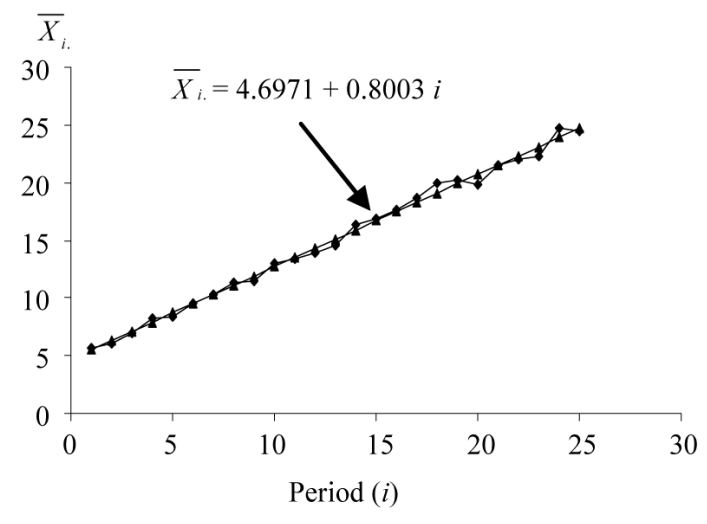

(b) Periodic means

Figure 1. Time plot of actual series and periodic means of simulated series using Equation (9). 


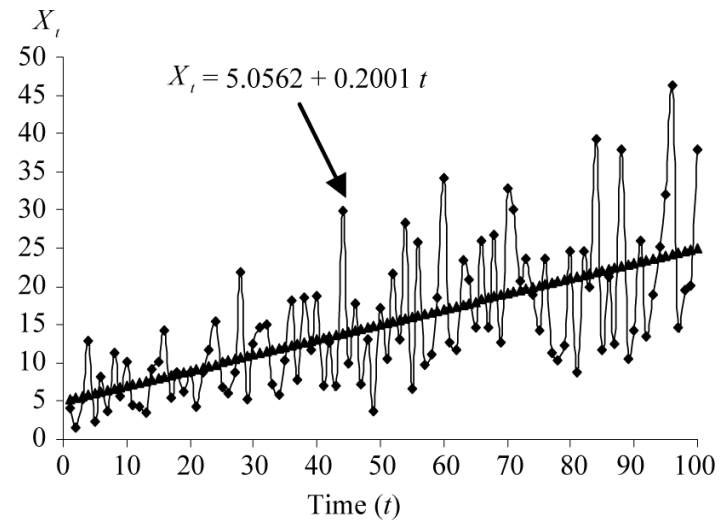

(a) Actual series

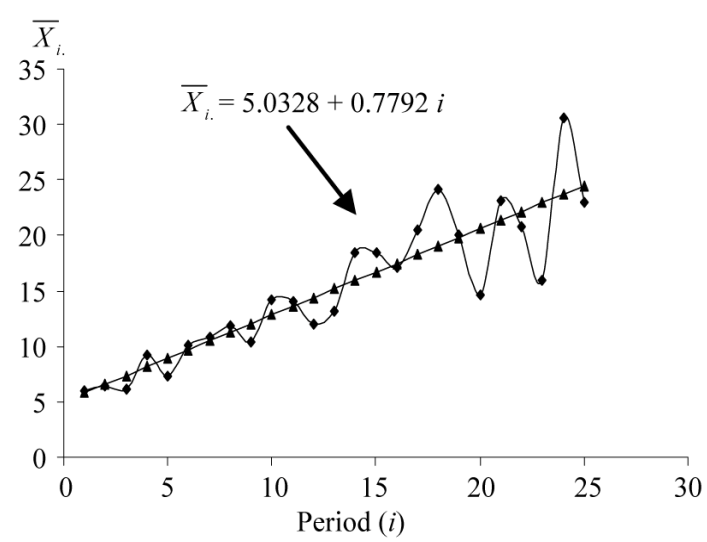

(b) Periodic means

Figure 2. Time plot of actual series and periodic means of simulated series using Equation (10).

\subsection{Quadratic Trend}

The data of Table 4 (quadratic trend and additive model) and Figure 3 is a simulation of 100 values from the additive model

$$
X_{t}=\left(a+b t+c t^{2}\right)+S_{t}+e_{t}
$$

with $s=4, \quad a=5.0, \quad b=-0.35, \quad c=0.35, \quad S_{1}=-50$, $S_{2}=30, \quad S_{3}=80, \quad S_{4}=-60$ and $e_{t} \sim N(0,1)$. The data of Table 4 (quadratic trend and multiplicative model) and Figure 4 is a simulation of 100 values from the multiplicative model

$$
X_{t}=\left(a+b t+c t^{2}\right) \times S_{t} \times e_{t}
$$

with $s=4, \quad a=5.0, \quad b=-0.35, \quad c=0.35, \quad S_{1}=0.6$, $S_{2}=1.1, \quad S_{3}=0.9, \quad S_{4}=1.4$ and $e_{t} \sim N\left(1,0.333^{2}\right)$ white noise. Listed in Table 4 are the periodic/row means $\left(\bar{X}_{i,}, i=1,2, \cdots, m\right)$ of the simulated data, while the time plots of the actual series and periodic/row means are shown in Figure 3 and Figure 4, respectively.

Figures $\mathbf{3}$ and $\mathbf{4}$ show that the graphs of the periodic means follow the same pattern as the plot of the actual series with respect to quadratic trend in both the additive and multiplicative models. Thus, as in the linear trend, one may look at only the plot of the periodic means in order to choose the appropriate trend. As in linear trend also, the estimate of the parameters of the trend of the entire series can be determined from the estimate of the trend of the periodic means by recognizing that periodic averages are centred at the midpoints of the periodic intervals. That is, periodic averages, $\bar{X}_{i .}, i=1,2, \cdots, m$ may be expressed in terms of the original series at times $t_{i},=1,2, \cdots, m$ as

$$
\bar{X}_{i .}=X_{t_{i}}=a+b t_{i}+c t_{1}^{2}
$$

$$
\begin{aligned}
= & a+b\left(\frac{(2 i-1) s+1}{2}\right)+c\left(\frac{(2 i-1) s+1}{2}\right)^{2} \\
= & a-b\left(\frac{s-1}{2}\right)+c\left(\frac{s-1}{2}\right)^{2} \\
& +(b s-c s(s-1)) i+c(s)^{2} i^{2} \\
= & a^{\prime}+b^{\prime} i+c^{\prime} i^{2}
\end{aligned}
$$

where $a^{\prime}=a-b\left(\frac{s-1}{2}\right)+c\left(\frac{s-1}{2}\right)^{2}, \quad b^{\prime}=(b s-c s(s-1))$ and $c^{\prime}=c(s)^{2}$

As an illustration, from Figure 4, the length of the periodic interval $s=4$, the parameters of the trend of the periodic averages are $a^{\prime}=6.6541, b^{\prime}=-5.5799$ and $c^{\prime}$ $=5.5992$. Hence, the parameters of the actual series are:

$$
\begin{aligned}
c & =\frac{c^{\prime}}{s^{2}}=\frac{5.5992}{4^{2}}=0.3500, \\
b & =\frac{b^{\prime}+c s(s-1)}{s} \\
& =\frac{-5.5799+(0.3500)(4)(4-1)}{4}=-0.3451 \\
a & =a^{\prime}+b\left(\frac{s-1}{2}\right)-c\left(\frac{s-1}{2}\right)^{2} \\
& =6.6541-0.3451\left(\frac{4-1}{2}\right)-0.3500\left(\frac{4-1}{2}\right)^{2} \\
& =5.3490
\end{aligned}
$$

\subsection{Exponential Trend}

The data of Table 4 (exponential trend and additive model) and Figure $\mathbf{5}$ is a simulation of 100 values from the additive model 


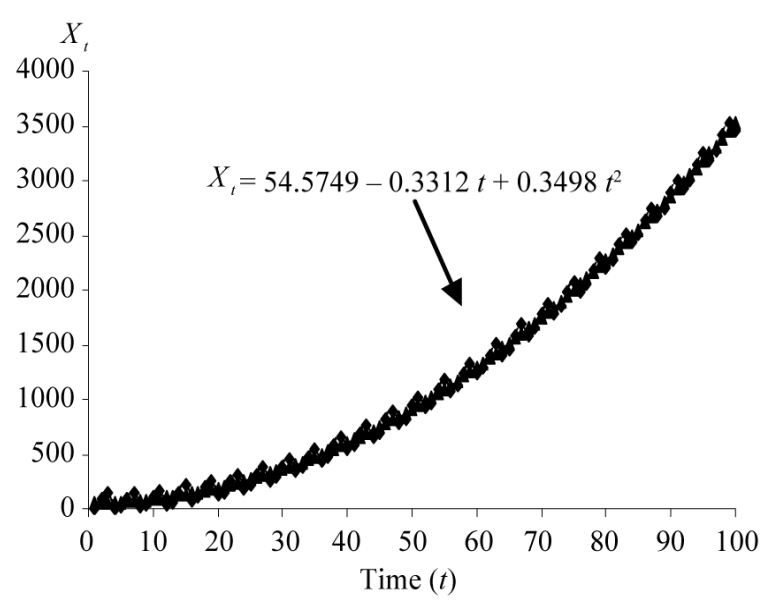

(a) Actual series

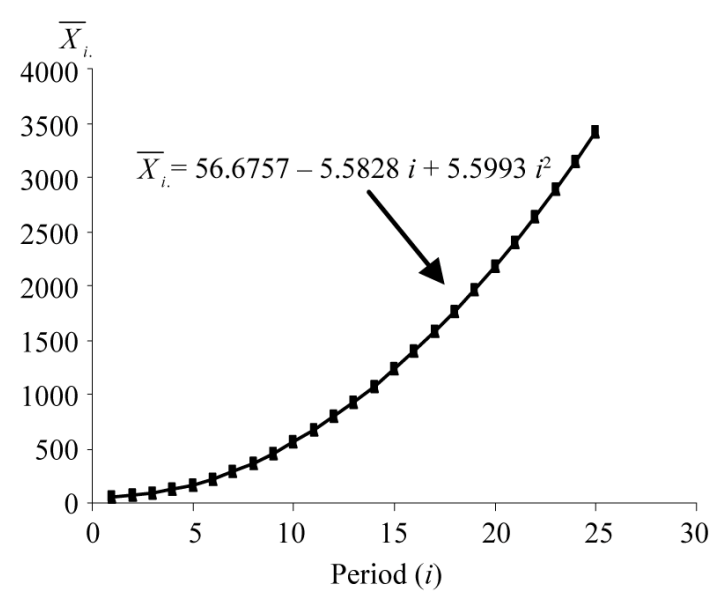

(b) Periodic means

Figure 3. Plot of actual series and periodic means of simulated series using Equation (13).

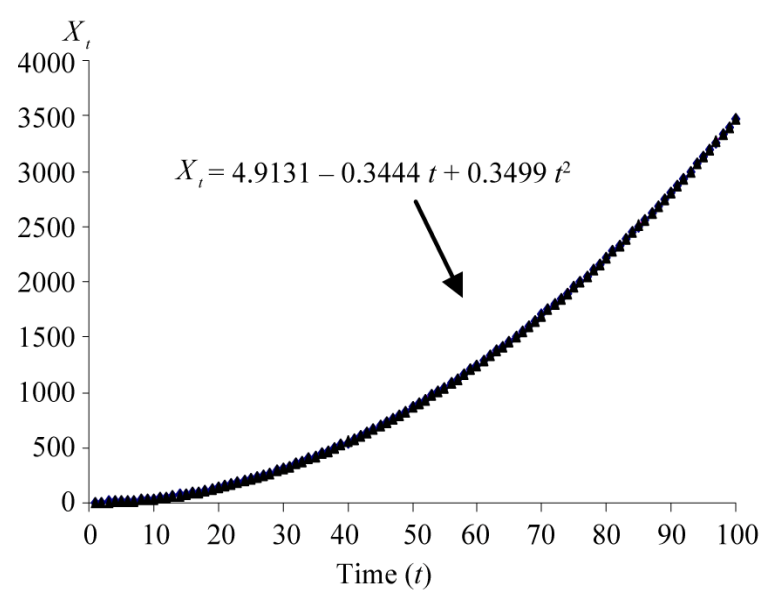

(a) Actual series

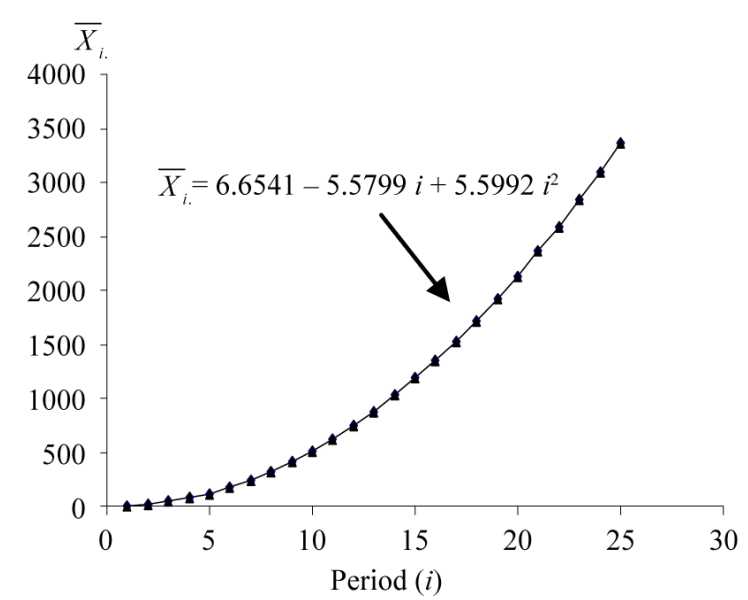

(b) Periodic means

Figure 4. Plot of actual series and periodic means of simulated series using Equation (14).

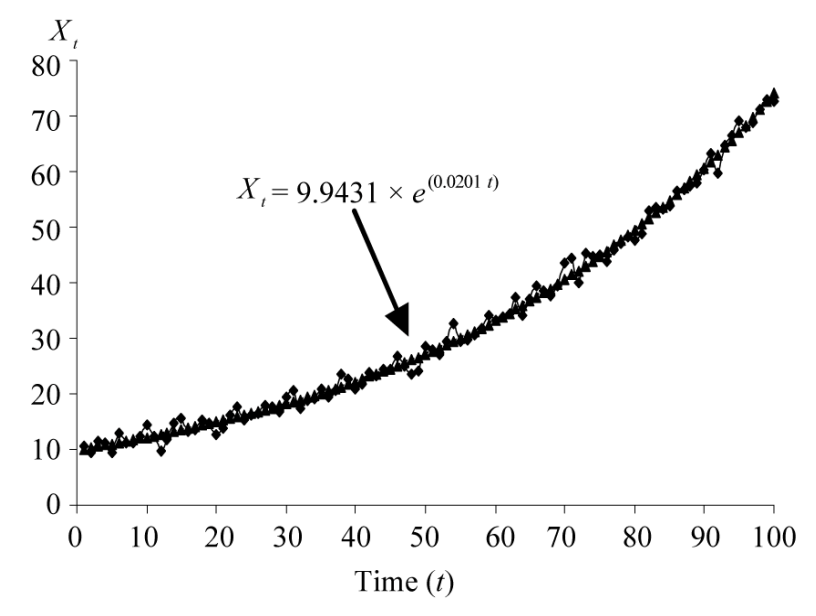

(a) Actual series

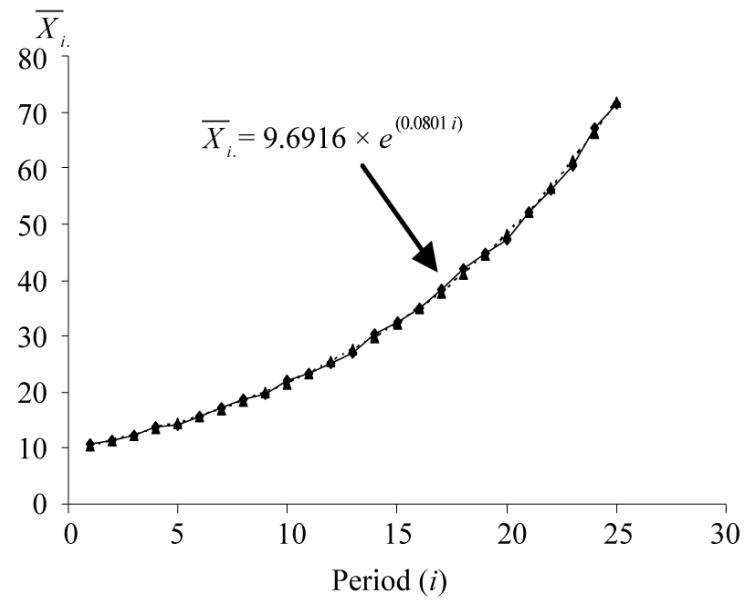

(b) Periodic means

Figure 5. Actual series and periodic means of simulated series from Equation (16). 


$$
X_{t}=b e^{c t}+S_{t}+e_{t}
$$

with $s=4, \quad b=10, \quad c=0.02, \quad S_{1}=-1.5, \quad S_{2}=2.5$, $S_{3}=3.5, \quad S_{4}=-4.5$ and $e_{t} \sim N(0,1)$. The data of Table 4 (exponential trend and multiplicative model) and Figure 6 is a simulation of 100 values from the multiplicative model

$$
X_{t}=b e^{c t} \times S_{t} \times e_{t}
$$

with $s=4, \quad b=10, \quad c=0.02, \quad S_{1}=0.6, \quad S_{2}=1.1, S_{3}$ $=0.9, \quad S_{4}=1.4$ and $e_{t} \sim N\left(1,0.333^{2}\right)$ white noise. Listed in Table 4 are the periodic/row means $\left(\bar{X}_{i .}\right.$, $i=1,2, \cdots, m)$ of the simulated data, while the time plots of the actual series and periodic/row means are shown in Figures 5 and 6, respectively.

The corresponding graphs of the actual series and the periodic means, shown in Figures 5 and $\mathbf{6}$, indicate clearly that the pattern in the plot of the periodic means is similar to that of the actual series in both the additive and multiplicative models.

As in linear and quadratic trend curves, the estimate of the parameters of the exponential trend of the entire series can be determined from the estimate of the trend of the periodic means. That is, periodic averages, $\bar{X}_{i}, i=$ $1,2, \cdots, m$ may be expressed in terms of the original series at times $t_{i}, i=1,2, \cdots, m$ as

$$
\begin{aligned}
\bar{X}_{i .} & =X_{t_{i}}=b e^{c t_{i}}=b e^{c\left[\frac{(2 i-1) s+1}{2}\right]} \\
& =\left(b e^{-c\left(\frac{s-1}{2}\right)}\right) e^{(c s) i}=b^{\prime} e^{c^{\prime} i}
\end{aligned}
$$

where $b^{\prime}=b e^{-c\left(\frac{s-1}{2}\right)}$ and $c^{\prime}=c s$.

As an illustration, from Figure 6 the length of the pe-

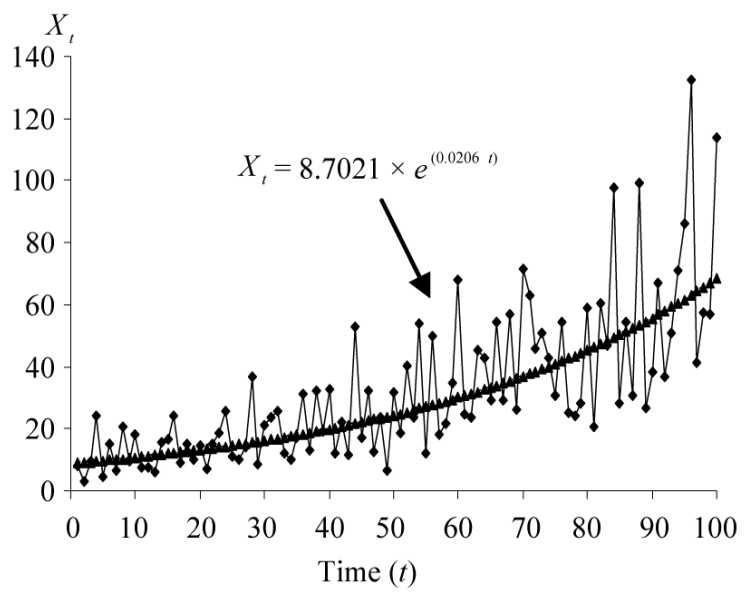

(a) Actual series riodic interval $s=4$, the parameters of the trend of the periodic averages are $b^{\prime}=9.9323$, and $c^{\prime}=0.0780$. Hence, the parameters of the actual series are:

$$
\begin{aligned}
& c=\frac{c^{\prime}}{s}=\frac{0.0780}{4}=0.0195, \\
& b=b^{\prime} e^{c\left(\frac{s-1}{2}\right)}=9.9323 \times e^{0.0195\left(\frac{4-1}{2}\right)}=10.2273
\end{aligned}
$$

\section{Assessment of Seasonal Component}

The seasonal component consists of effects that are reasonably stable with respect to timing, direction and magnitude. Seasonality in a time series can be identified from the time plot of the entire series by regularly spaced peaks and troughs which have a consistent direction and approximately the same magnitude every period/year, relative to the trend.

For time series which contain a seasonal effect, the overall average $\left(\bar{X}_{. .}\right)$and the seasonal average $\left(\bar{X}_{. j}\right.$, $j=1,2, \cdots, s)$ of the Buys-Ballot table are used to assess the effects either as a difference $\left(\bar{X}_{. j}-\bar{X}_{. .}\right)$or as a ratio $\left(\bar{X}_{. j} / \bar{X}_{. .}\right)$. That is, the deviations of the differences seasonal averages and the overall average (additive model) from zero or the ratios of the seasonal averages to the overall average from unity (multiplicative model) is used to assess the presence of seasonal effect. The wider the deviations, the greater the seasonal effect.

This is illustrated below with stimulated time series data for the additive and multiplicative models when trend-cycle components are assumed 1) linear (Equations (9) and (10), respectively) 2) quadratic (Equations (13) and (14), respectively) and 3) exponential (Equations (16) and (17), respectively). The assessed values of the sea-

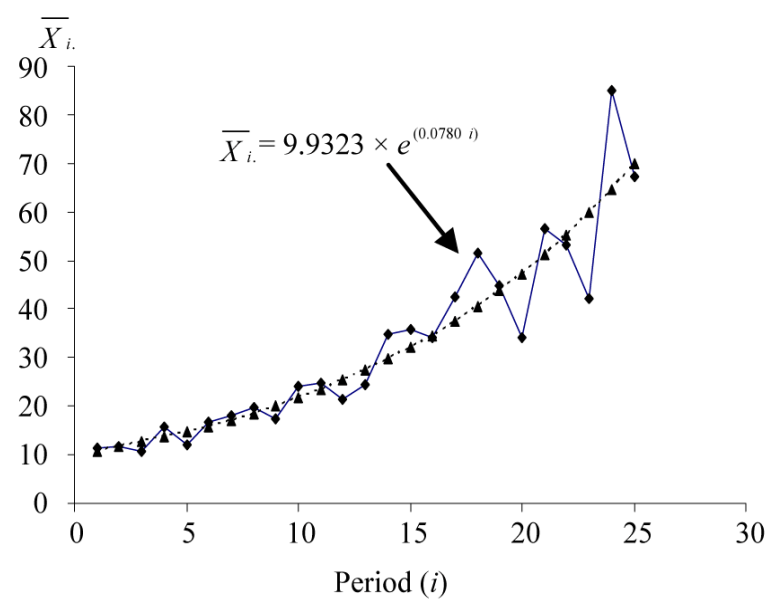

(b) Periodic means

Figure 6. Actual series and periodic means of simulated series from Equation (17). 
sonal effects from these series are given in Table $\mathbf{5}$ while their corresponding graphs are given in Figures 7, 8 and 9 respectively. As Table 5 and Figures 7, 8 and 9 show, the patterns of the deviations $\bar{X}_{. j}-\bar{X}_{\text {.. }}$ (additive model) of the seasonal averages $\left(\bar{X}_{. j}\right)$ from the overall average $\left(\bar{X}_{. .}\right)$and ratios $\bar{X}_{. j} / \bar{X}_{. .}$(multiplicative model) mimics/follow those of the actual seasonal indices $S_{j}$ used in the simulation in all series. Thus, an analyst interested in studying the seasonal effect in any study series only needs to look at either $\bar{X}_{. j}-\bar{X}_{. .}$or $\bar{X}_{. j} / \bar{X}_{. .}$to determine if there is seasonal effect or not.

However, this should not be used as a conclusive test for the presence of or otherwise of seasonal effect in a study series. The use of seasonal averages to measure seasonal effect is most appropriate in a series with no trend. When trend dominates other components in any series, the true seasonal effect may be visible from $\bar{X}_{. j}-\bar{X}_{. .}$or $\bar{X}_{. j} / \bar{X}_{. .}$. Therefore, this assessment procedure should be used with great caution.

\section{Choice of Appropriate Model}

Traditionally, the time plot of the entire series is used to make the appropriate choice between the additive and multiplicative models. In some time series, the amplitude of both the seasonal and irregular variations do not change as the level of the trend rises or falls. In such cases, an additive model is appropriate. In many time series, the amplitude of both the seasonal and irregular variations increases as the level of the trend rises. In this situation, a multiplicative model is usually appropriate. The multiplicative model cannot be used when the original time series contains very small or zero values. This is because it is not possible to divide a number by zero. In these cases, a pseudo-additive model combining the elements of both the additive and multiplicative models is used.

How can an appropriate model be obtained from the parameters of the Buys-Ballot table? The relationship between the seasonal means $\left(\bar{X}_{. j}, j=1,2, \cdots, s\right)$ and the

Table 5. Actual values of seasonal effects $\left(S_{j}\right)$, deviations of seasonal averages from the overall averages $\left(\bar{X}_{. j}-\bar{X}_{. .}\right)$and ratios of seasonal averages to the overall averages $\left(\bar{X}_{. j} / \bar{X}_{. .}\right)$for the simulated series.

\begin{tabular}{|c|c|c|c|c|c|c|c|c|c|c|c|c|}
\hline \multirow{3}{*}{ Season $j$} & \multicolumn{4}{|c|}{ Linear } & \multicolumn{4}{|c|}{ Quadratic } & \multicolumn{4}{|c|}{ Exponential } \\
\hline & \multicolumn{2}{|c|}{$\begin{array}{c}\text { Additive } \\
\text { Equation (9) }\end{array}$} & \multicolumn{2}{|c|}{$\begin{array}{l}\text { Multiplicative } \\
\text { Equation (10) }\end{array}$} & \multicolumn{2}{|c|}{$\begin{array}{c}\text { Additive } \\
\text { Equation (13) }\end{array}$} & \multicolumn{2}{|c|}{$\begin{array}{l}\text { Multiplicative } \\
\text { Equation (14) }\end{array}$} & \multicolumn{2}{|c|}{$\begin{array}{c}\text { Additive } \\
\text { Equation (16) }\end{array}$} & \multicolumn{2}{|c|}{$\begin{array}{l}\text { Multiplicative } \\
\text { Equation (17) }\end{array}$} \\
\hline & $S_{j}$ & $\bar{X}_{. j}-\bar{X}_{. .}$ & $S_{j}$ & $\bar{X}_{. j}-\bar{X}$ & $S_{j}$ & $\bar{X}_{. j}-\bar{X}_{. .}$ & $S_{j}$ & $\bar{X}_{. j}-\bar{X}_{. .}$ & $S_{j}$ & $\bar{X}_{. j}-\bar{X}$ & $S_{j}$ & $\bar{X}_{. j}-\bar{X}$ \\
\hline 1 & -1.5 & -1.71 & 0.61 & 0.62 & -50 & -103.0 & 0.6 & 0.60 & -0.6 & -1.47 & 0.6 & 0.61 \\
\hline 2 & 2.5 & 2.24 & 1.08 & 1.01 & 30 & 12.00 & 1.1 & 0.99 & 1.1 & 0.62 & 1.1 & 1.01 \\
\hline 3 & 3.5 & 3.47 & 0.93 & 0.90 & 80 & 97.00 & 0.9 & 0.90 & 0.9 & 1.09 & 0.9 & 0.89 \\
\hline 4 & -4.5 & -4.01 & 1.38 & 1.47 & -60 & -7.00 & 1.4 & 1.51 & -1.4 & -0.24 & 1.4 & 1.50 \\
\hline
\end{tabular}

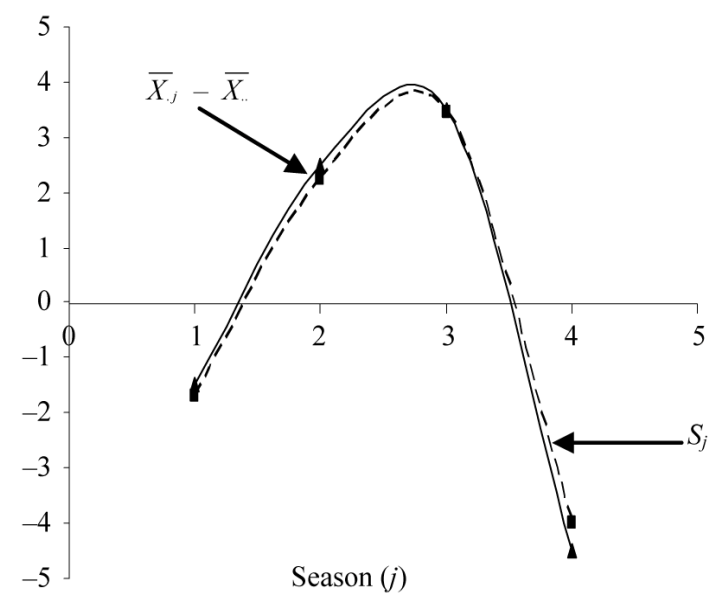

(a) Additive model

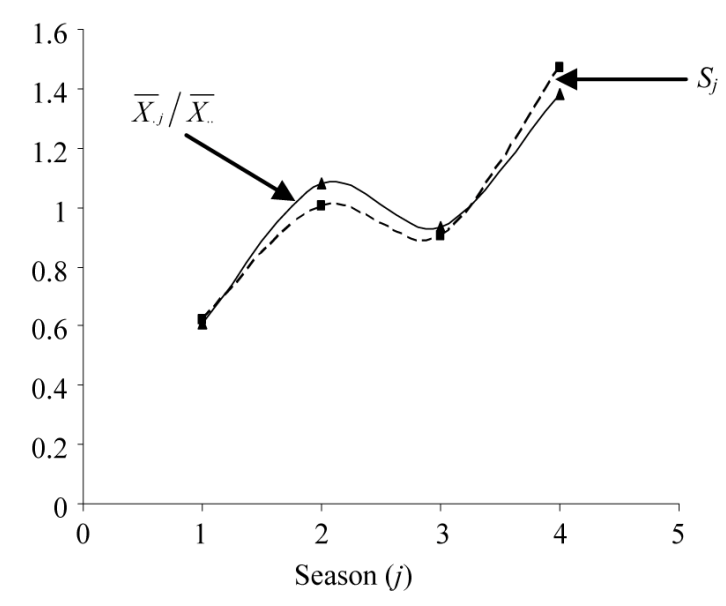

(b) Multiplicative model

Figure 7. Assessment of seasonal effects when trend is linear. 


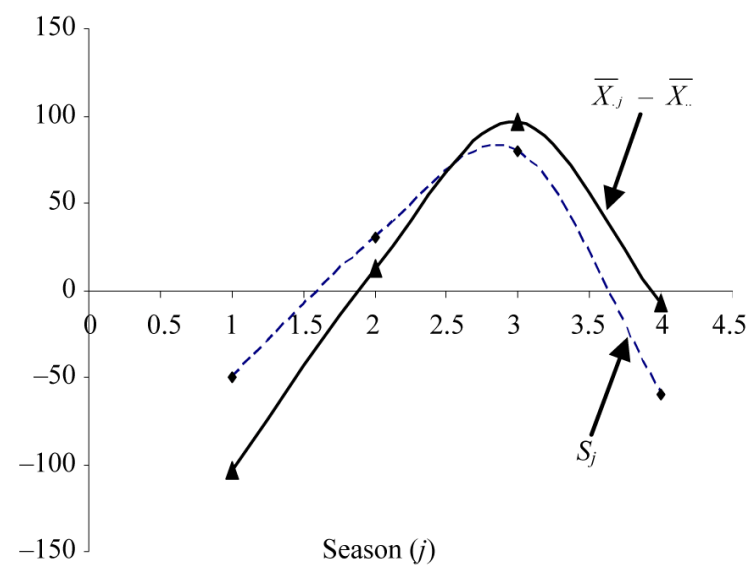

(a) Additive model

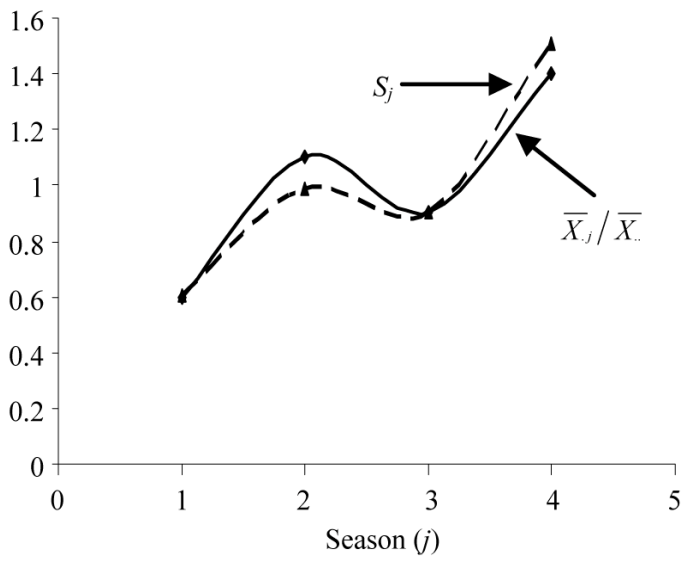

(b) Multiplicative model

Figure 8. Assessment of seasonal effect when trend is quadratic.

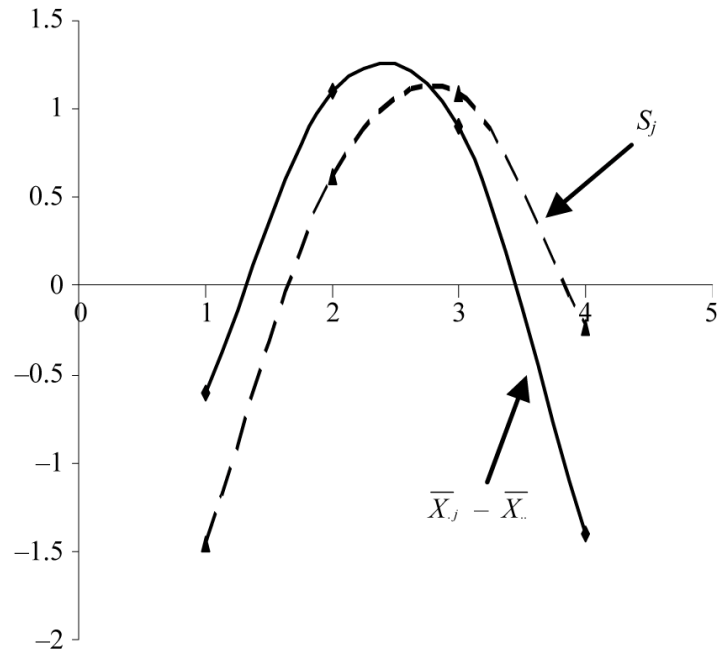

Season $(j)$

(a) Additive model

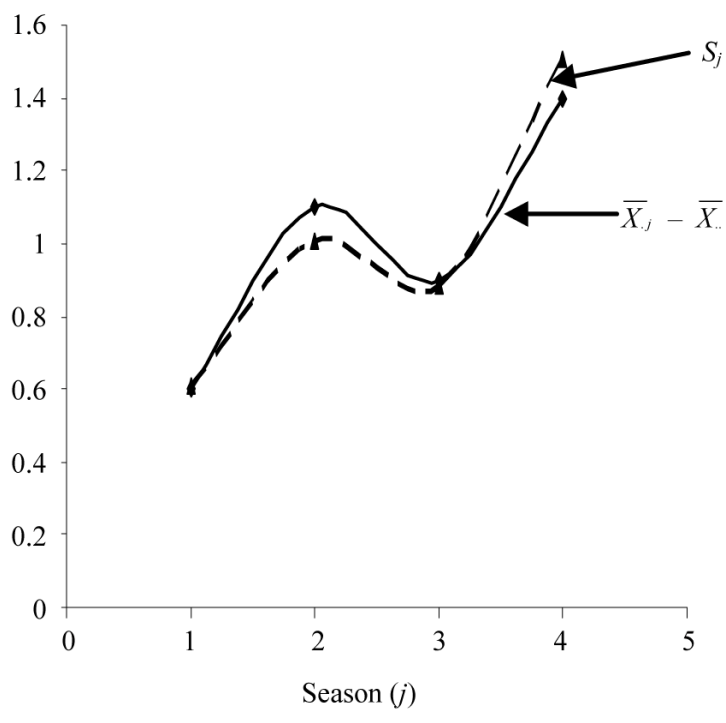

(b) Multiplicative model

Figure 9. Assessment of seasonal effect when trend is exponential.

seasonal standard deviations $\left(\hat{\sigma}_{. j}, j=1,2, \cdots, s\right)$ gives an indication of the desired model. An additive model is appropriate when the seasonal standard deviations show no appreciable increase/decrease relative to any increase or decrease in the seasonal means. On the other hand, a multiplicative model is usually appropriate when the seasonal standard deviations show appreciable increase/decrease relative to any increase/decrease in the seasonal means. This is vividly demonstrated in Table 6 for additive and multiplicative models. Time plots of $\bar{X}_{. j}$ and $\hat{\sigma}_{. j},(j=1,2, \cdots, s)$ are given in Figures 10 through 12 for values of Table 6 .

As Tables 6 and Figures 10 through 12 show, the observations are true for all trending curves and for both additive and multiplicative models. For the multiplicative model, the plot of standard deviation, $\left(\hat{\sigma}_{. j}\right)$ clearly show appreciable increase or decrease as the seasonal averages $\left(\bar{X}_{. j}\right)$ change. For the additive model, the plot of $\left(\hat{\sigma}_{. j}\right)$ show no appreciable change relative to the plot of seasonal averages $\left(\bar{X}_{. j}\right)$ in all the series. However, as noted earlier, when trend dominates other components, the seasonal standard deviations may not follow the observed pattern and therefore, may not be used effectively for choice of appropriate model for decomposition. Therefore, the use of the plot of the seasonal averages and standard deviations as basis for the choice of appropriate model should be done with great care. 
Table 6. Seasonal means and standard deviations for the simulated series.

\begin{tabular}{|c|c|c|c|c|c|c|c|c|c|c|c|c|}
\hline \multirow{3}{*}{ Season $j$} & \multicolumn{4}{|c|}{ Linear } & \multicolumn{4}{|c|}{ Quadratic } & \multicolumn{4}{|c|}{ Exponential } \\
\hline & \multicolumn{2}{|c|}{$\begin{array}{c}\text { Additive } \\
\text { Equation (9) }\end{array}$} & \multicolumn{2}{|c|}{$\begin{array}{l}\text { Multiplicative } \\
\text { Equation (10) }\end{array}$} & \multicolumn{2}{|c|}{$\begin{array}{c}\text { Additive } \\
\text { Equation (13) }\end{array}$} & \multicolumn{2}{|c|}{$\begin{array}{l}\text { Multiplicative } \\
\text { Equation (14) }\end{array}$} & \multicolumn{2}{|c|}{$\begin{array}{c}\text { Additive } \\
\text { Equation (16) }\end{array}$} & \multicolumn{2}{|c|}{$\begin{array}{l}\text { Multiplicative } \\
\text { Equation (17) }\end{array}$} \\
\hline & $\bar{X}_{. j}$ & $\hat{\sigma}_{j}$ & $\bar{X}_{. j}$ & $\hat{\sigma}_{j}$ & $\bar{X}_{. j}$ & $\hat{\sigma}_{j}$ & $\bar{X}_{. j}$ & $\hat{\sigma}_{j}$ & $\bar{X}_{. j}$ & $\hat{\sigma}_{j}$ & $\bar{X}_{. j}$ & $\hat{\sigma}_{j}$ \\
\hline 1 & 13.40 & 6.05 & 9.41 & 5.13 & 1119 & 1034 & 708 & 707 & 30.8 & 17.95 & 19.61 & 13.28 \\
\hline 2 & 17.34 & 5.94 & 15.25 & 7.89 & 1234 & 1054 & 1161 & 1068 & 32.88 & 18.14 & 32.56 & 20.08 \\
\hline 3 & 18.57 & 6.07 & 13.7 & 7.83 & 1319 & 1074 & 1058 & 1113 & c & 18.72 & 28.68 & 21.11 \\
\hline 4 & 11.09 & 5.84 & 22.29 & 10.55 & 1215 & 1094 & 1772 & 1740 & 32.03 & 18.88 & 48.64 & 31.8 \\
\hline
\end{tabular}

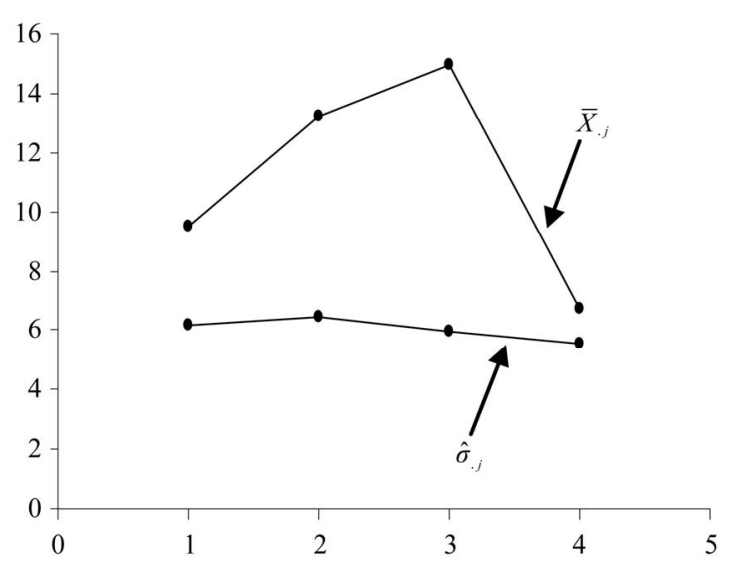

(a) Additive model

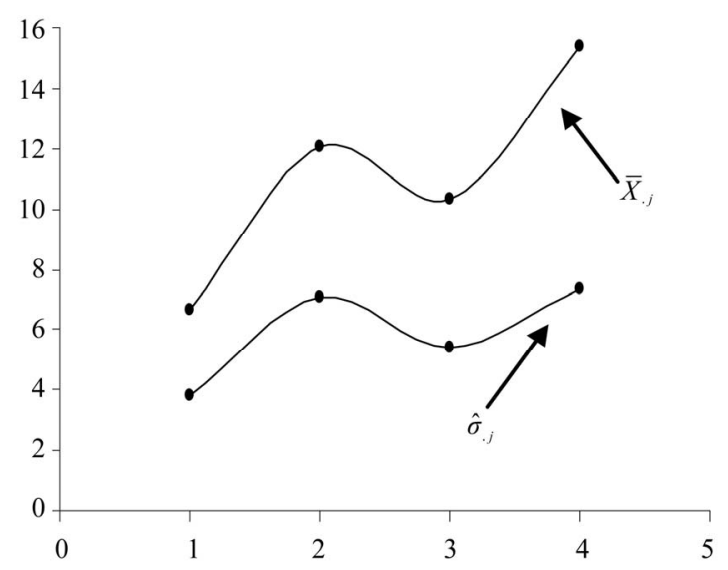

(b) Multiplicative model

Figure 10. Line plot of $\bar{X}_{. j}$ and $\hat{\sigma}_{. j}$ for simulated data when trend is linear (Equations 9 and 10).

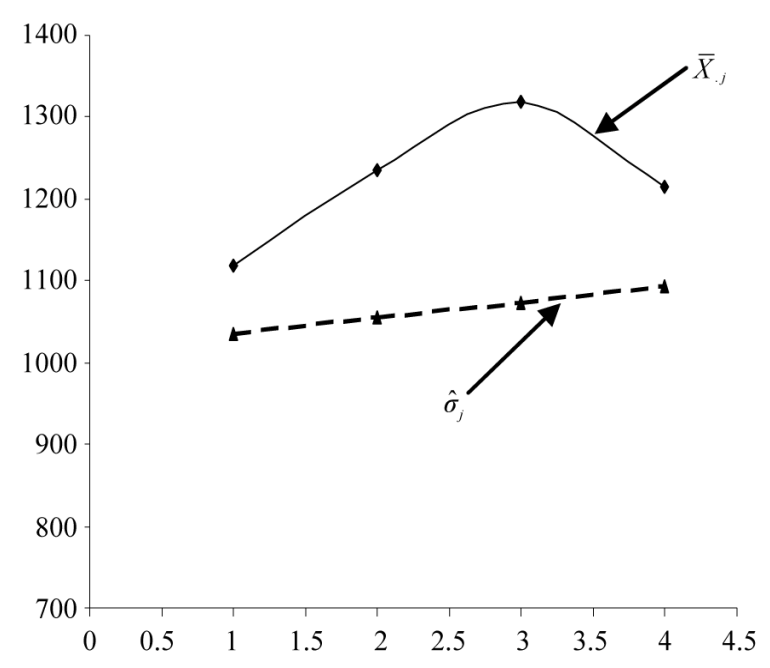

(a) Additive model

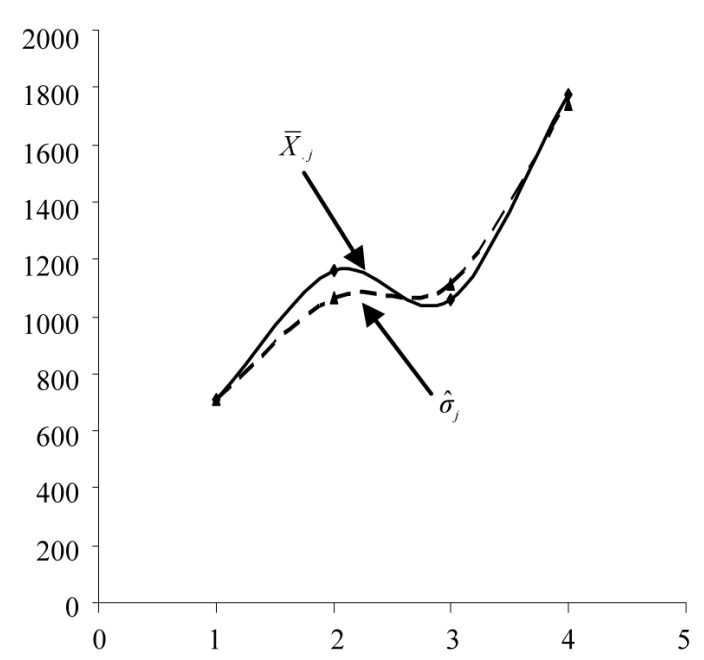

(b) Multiplicative model

Figure 11. Seasonal means $\left(\bar{X}_{. j}\right)$ and standard deviations $\left(\hat{\sigma}_{j}\right)$ of simulated series from quadratic trend (Equations 13 and 14). 


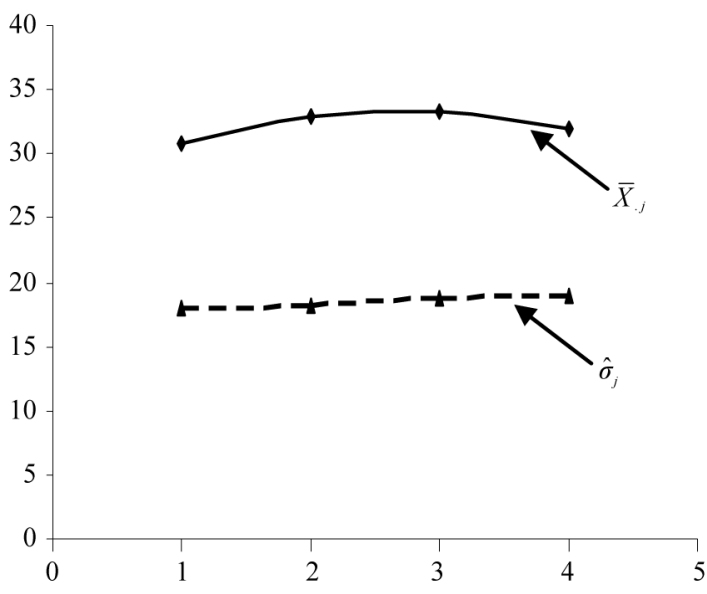

(a) Additive model

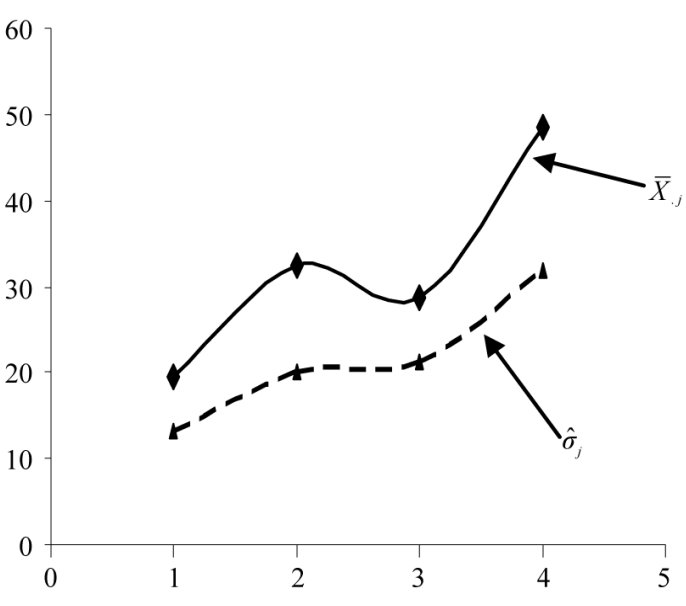

(b) Multiplicative model

Figure 12. Seasonal means $\left(\bar{X}_{. j}\right)$ and standard deviations $\left(\hat{\sigma}_{j}\right)$ of simulated series from exponential trend.

\section{Conclusions}

This paper has examined four uses of the Buys-Ballot table. Uses examined in detail include 1) data transformation 2) assessment of trend 3) assessment of seasonality and 4) choice of model for decomposition. Use of Buys-Ballot table for the estimation of trend and computation of seasonal indices was not discussed in details. For data transformation, the relationship between period /annual averages and standard deviations was used. Assessment of trend is based on the period/annual averages while the assessment of the seasonal effect is based on the seasonal and overall averages. The choice of appropriate model for decomposition is based on the seasonal averages and standard deviations.

\section{References}

[1] C. Chatfield, "The Analysis of Time Series: An Introduction,” Chapman and Hall/CRC Press, Boca Raton, 2004.

[2] D. B. Percival and A. T. Walden, "Wavelet Methods for Time Series Analysis,” Cambridge University Press, Cambridge, 2000.

[3] M. B. Priestley, "Spectral Analysis and Time Series Analysis,” Academic Press, London, Vols. 1-2, 1981.

[4] G. E. P. Box, G. M. Jenkins and G. C. Reinsel, "Time Series Analysis, Forecasting and Control," 3rd Edition, Prentice-Hall, Englewood Cliffs, 1994.

[5] W. W. S. Wei, "Time Series Analysis: Univariate and Multivariate Methods,” Addison-Wesley, Redwood City, 1989.

[6] M. G. Kendal and J. K. Ord, “Time Series,” 3rd Edition, Charles Griffin, London, 1990.

[7] G. M. Ljung and G. E. P. Box, "On a Measure of Lack of
Fit in Time Series Models,” Biometrika, Vol. 65, No. 2, 1978, pp. 297-303. doi:10.1093/biomet/65.2.297

[8] H. Wold, "A Study in the Analysis of Stationary Time Series,” 2nd Edition, Almqrist and Witsett, Stockholm, 1938.

[9] C. H. D. Buys-Ballot, "Leo Claemert Periodiques de Temperature,” Kemint et Fills, Utrecht, 1847.

[10] I. S. Iwueze and A. C. Akpanta, "Effect of the Logarithmic Transformation on the Trend-Cycle Component," Journal of Applied Science, Vol. 7, No. 17, 2007, pp. 2414-2422.

[11] I. S. Iwueze and E. C. Nwogu, "Buys-Ballot Estimates for Time Series Decomposition,” Global Journal of Mathematics, Vol. 3, No. 2, 2004, pp. 83-98.

[12] I. S. Iwueze and J. Ohakwe, "Buys-Ballot Estimates When Stochastic Trend is Quadratic," Journal of the Nigerian Association of Mathematical Physics, Vol. 8, 2004, pp. 311-318.

[13] I. S. Iwueze and E. C. Nwogu "Buys-Ballot Estimates for Exponential and S-Shaped Curves, for Time Series," Journal of the Nigerian Association of Mathematical Physics, Vol. 9, 2005, pp 357-366.

[14] I. S. Iwueze, E. C. Nwogu and J. C. Ajaraogu, "Properties of the Buys-Ballot Estimates When Trend-Cycle Component of a Time Series is Linear: Additive Case," International Journal of Methematics and Computation, Vol. 8, No. S10, 2010, pp. 18-27.

[15] G. E. P. Box and D. R. Cox, "An Analysis of Transformations," Journal of the Royal Statistical Society, Series B, Vol. 26, No. 2, 1964, pp. 211-243.

[16] A. C. Akpanta and I. S. Iwueze, "On Applying the Bartlett Transformation Method to Time Series Data," Journal of Mathematical Sciences, Vol. 20, No. 3, 2009, pp. 227-243.

[17] M. S. Bartlett, “The Use of Transformations," Biometrika, Vol. 3, 1947, pp. 39-52. 
[18] R. V. Hogg and A. T. Craig, "Introduction to Mathematical Statistics,” 4th Edition, MacMillan Publishing Company, New York, 1978.
[19] Central Bank of Nigeria, The Statistical Bulletin, Vol. 18, 2007.

\section{Appendix}

All Shares Index of the Nigerian Stock Exchange (1985-2005)

\begin{tabular}{|c|c|c|c|c|c|c|c|c|c|c|c|c|c|c|}
\hline \multirow{2}{*}{ Year } & \multicolumn{12}{|c|}{ Month } & \multirow{2}{*}{$\bar{X}_{i}$} & \multirow{2}{*}{$\hat{\sigma}_{i .}$} \\
\hline & Jan. & Feb. & Mar. & Apr. & May & June & July & Aug. & Sept. & Oct. & Nov. & Dec. & & \\
\hline 1985 & 111.3 & 112.2 & 113.4 & 115.6 & 116.5 & 116.3 & 117.2 & 117.0 & 116.9 & 119.1 & 124.6 & 127.3 & 117.3 & 4.7 \\
\hline 1986 & 134.6 & 139.7 & 140.8 & 146.2 & 144.2 & 147.4 & 150.9 & 151.0 & 155.0 & 160.9 & 163.3 & 163.8 & 149.8 & 9.5 \\
\hline 1987 & 166.9 & 166.2 & 161.7 & 157.5 & 154.2 & 196.1 & 193.4 & 193.0 & 194.9 & 154.8 & 193.4 & 190.9 & 176.9 & 17.9 \\
\hline 1988 & 190.8 & 191.4 & 195.5 & 200.1 & 199.2 & 206.0 & 211.5 & 217.6 & 224.1 & 228.5 & 231.4 & 233.6 & 210.8 & 15.9 \\
\hline 1989 & 239.7 & 251.0 & 256.9 & 257.5 & 257.1 & 259.2 & 269.2 & 281.0 & 279.9 & 298.4 & 311.2 & 325.3 & 273.9 & 26.1 \\
\hline 1990 & 343.0 & 349.3 & 356.0 & 362.0 & 382.3 & 417.4 & 445.4 & 463.6 & 468.2 & 480.3 & 502.6 & 513.8 & 423.7 & 63.1 \\
\hline 1991 & 528.7 & 557.0 & 601.0 & 625.0 & 649.0 & 651.8 & 688.0 & 712.1 & 737.3 & 757.5 & 769.0 & 783.0 & 671.6 & 83.7 \\
\hline 1992 & 794.0 & 810.7 & 839.1 & 844.0 & 860.5 & 870.8 & 879.7 & 969.3 & 1022.0 & 1076.5 & 1098.0 & 1107.6 & 931.0 & 117.0 \\
\hline 1993 & 1113.4 & 1119.9 & 1130.5 & 1147.3 & 1186.9 & 1187.5 & 1180.8 & 1195.5 & 1217.3 & 1310.9 & 1414.5 & 1543.8 & 1229.0 & 131.1 \\
\hline 1994 & 1666.3 & 1715.3 & 1792.8 & 1845.6 & 1875.5 & 1919.1 & 1926.3 & 1914.1 & 1956.0 & 2023.4 & 2119.3 & 2205.0 & 1913.2 & 154.5 \\
\hline 1995 & 2285.3 & 2379.8 & 2551.1 & 2785.5 & 3100.8 & 3586.5 & 4314.3 & 4664.6 & 4858.1 & 5068.0 & 5095.2 & 5092.2 & 3815.0 & 1149.0 \\
\hline 1996 & 5135.1 & 5180.4 & 5266.2 & 5412.4 & 5704.1 & 5798.7 & 5919.4 & 6141.0 & 6501.9 & 6634.8 & 6775.6 & 6992.1 & 5955.0 & 652.0 \\
\hline 1997 & 7268.3 & 7699.3 & 8561.4 & 8729.8 & 8592.3 & 8459.3 & 8148.8 & 7682.0 & 7130.8 & 6554.8 & 6395.8 & 6440.5 & 7639.0 & 876.0 \\
\hline 1999 & 5494.8 & 5376.5 & 5456.2 & 5315.7 & 5315.7 & 5977.9 & 4964.4 & 4946.2 & 4890.8 & 5032.5 & 5133.2 & 5266.4 & 5264.2 & 304.3 \\
\hline 2000 & 5752.9 & 5955.7 & 5966.2 & 5892.8 & 6095.4 & 6466.7 & 6900.7 & 7394.1 & 7298.9 & 7415.3 & 7164.4 & 8111.0 & 6701.0 & 778.0 \\
\hline 2001 & 8794.2 & 9180.5 & 9159.8 & 9591.6 & 10153.8 & 10937.3 & 10576.4 & 10329.0 & 10274.2 & 11091.4 & 11169.6 & 10963.1 & 10185.0 & 825.0 \\
\hline 2002 & 10650.0 & 10581.9 & 11214.4 & 11399.1 & 11486.7 & 12440.7 & 12458.2 & 12327.9 & 11811.6 & 11451.5 & 11622.7 & 12137.7 & 11632.0 & 637.0 \\
\hline 2003 & 13298.8 & 13668.8 & 13531.1 & 13488.0 & 14086.3 & 14565.5 & 13962.0 & 15426.0 & 16500.5 & 18743.5 & 19319.3 & 20128.9 & 15560.0 & 2502.0 \\
\hline 2004 & 22712.9 & 24797.4 & 22896.4 & 25793.0 & 27730.8 & 28887.4 & 27062.1 & 23774.3 & 22739.7 & 23354.8 & 23270.5 & 23844.5 & 24739.0 & 2131.0 \\
\hline 2005 & 23078.3 & 21953.5 & 20682.4 & 21961.7 & 21482.1 & 21564.8 & 21911.0 & 22935.4 & 24635.9 & 25873.8 & 24635.9 & 24085.8 & 22877.0 & 1563.0 \\
\hline $\bar{X}_{. j}$ & 5533.1 & 5648.2 & 5579.6 & 5818.3 & 5981.3 & 6216.6 & 6099.8 & 6077.6 & 6129.1 & 6357.2 & 6329.4 & 6472.8 & 6020.3 & \\
\hline$\hat{\sigma}_{. j}$ & 6955.2 & 7116.6 & 6743.2 & 7281.1 & 7539.4 & 7782.9 & 7503.3 & 7246.9 & 7369.4 & 7761.4 & 7609.5 & 7723.7 & & 7235.3 \\
\hline
\end{tabular}

Source: Statistical Bulletin of the Central Bank of Nigeria (CBN, 2007) 